\title{
Initial cracking strength and initial fracture toughness from 3-p-b and WS concrete specimens
}

Xianhua Yao ${ }^{1}$, Lielie $\mathrm{Li}^{2}$, Junfeng Guan ${ }^{1}$, Min Zhang ${ }^{1}$, Zepeng Liu ${ }^{1}$, Ruicong Han ${ }^{1}$, and Shuanghua $\mathrm{He}^{1}$

${ }^{1}$ North China University of Water Resources and Electric Power

${ }^{2}$ North-China University of Water Conservancy and Electric Power

July 11, 2020

\begin{abstract}
A concept of initial cracking strength of concrete is elaborated in this study. A fracture model and associated methods for determining independent initial cracking strength and initial fracture toughness by using the three-point-bending (3-p-b) and wedge splitting (WS) concrete specimens are present. The initial cracking strength and initial fracture toughness can be simultaneously determined using a curve-fitting method from the proposed fracture model. All of the initial fracture curves can be obtained using the determined concrete materials. The initial loads of the 3 -p-b and WS specimens can be predicted on the basis of the curves with $\pm 15 \%$ ranges. Furthermore, analytical functions are used to obtain and determine the initial cracking strength and the initial fracture toughness of concretes directly. The determined values with $\pm 15 \%$ ranges cover the most of initial loads of the 3-p-b and WS specimens.
\end{abstract}

\section{Hosted file}

20200711NEW Manuscript for initial cracking.docx available at https://authorea.com/users/ 341870/articles/468770-initial-cracking-strength-and-initial-fracture-toughness-from-3$\mathrm{p}$-b-and-ws-concrete-specimens 